\title{
Back Pressure Equal Channel Angular Pressing of Consolidate Pure Al Particles
}

\author{
Li Yinglong ${ }^{1,2,3, *}, \mathrm{He} \mathrm{Lizi}^{4}$, Zhang Ling ${ }^{1,2,3,5}$ \\ ${ }^{1}$ School of Materials Science and Engineering, Northeastern University, Shenyang, P. R. China \\ ${ }^{2}$ State Key Laboratory of Rolling and Automation, Northeastern University, Shenyang, P. R. China \\ ${ }^{3}$ Laboratory of Lightweight Structural Materials, Shenyang, P. R. China \\ ${ }^{4} \mathrm{Key}$ Lab of Electromagnetic Processing of Materials, Northeastern University, Shenyang, P. R. China \\ ${ }^{5}$ School of Mechanical and Engineering, Ningxia Institute of Technology, Shizuishan, P. R. China
}

Email address:

liyl@mail.neu.edu.cn (Li Yinglong), 1810239@stu.neu.edu.cn (Li Yinglong)

${ }^{*}$ Corresponding author

\section{To cite this article:}

Li Yinglong, He Lizi, Zhang Ling. Back Pressure Equal Channel Angular Pressing of Consolidate Pure Al Particles. International Journal of Materials Science and Applications. Vol. 9, No. 1, 2020, pp. 1-6. doi: 10.11648/j.ijmsa.20200901.11

Received: December 11, 2019; Accepted: January 31, 2020; Published: February 3, 2020

\begin{abstract}
In this study, pure aluminum particles were successfully consolidated to fully dense bulk material by back pressure equal channel angular pressing (BE-ECAP) at room temperature, the evolutions of microstructure and densification mechanism were systematically investigated using an FEI-TECNAI G20 transmission electron microscope (TEM) operating at 200kV, FEI field-emission scanning electron microscope (FE-SEM) and hardness testing. The results indicated that the strong bulk materials from particles were successfully produced. After 4 BE-ECAP passes, the present samples show finer grains with the average grain size of $\sim 10 \mu \mathrm{m}$, the density of the sample was considerably higher compared to those of the materials that had undergone ECAP without back pressure, and was approach to the theoretical density of pure Al. This was related to the combination of hydrostatic pressure, shear deformation and strain accumulation. The mechanisms of grain refinement was the dislocation generated inside grains moves towards the grain boundary continuously, and accumulates, tangles annihilates at the grain boundaries, which resulting in the grains continuously fragmented and refined.
\end{abstract}

Keywords: Powder Consolidation, Back Pressure (BE), Equal Channel Angular Pressing (ECAP), Aluminum Particle

\section{Introduction}

The powder metallurgy and ceramic manufacturing has been used in synthesis of bulk materials from particles with specific shape, size and performance for a long time. However, it avoids large scale solidification processing and often results in composition segregation and casting defects, which is difficult to achieve the theoretical density and hardness. Compared with other dense materials, powder metallurgy products has weak plastic deformation ability, and it is easy to generate cracks during subsequent processing and hard to accumulate large effective strains or deform, which affects the effect of microstructure refinement and greatly reduces its strength and toughness. However, fully dense materials are difficult to produce using conventional powder metallurgy. More recently, severe deformation processes such as equal channel angular pressing [1-6], torsional-equal channel angular pressing (T-ECAP) [7-12], back pressure equal channel angular [13-15], and extrusion-equal channel angular pressing $[3,16]$ are mostly used to consolidate $\mathrm{Al}$ particles to superior dense components. ECAP deformation can effectively reduce the porosity, increase the relative density and consolidation effect, and was used to prepare particle reinforced aluminum-based composite materials [14, 17], especially the method of wrapped powder with the sheath, the severe shear deformation involved in these processes is believed to disrupt the surface oxide layer and create good contact between particles. Consequently, consolidation can be carried out at room temperature and even achieved fully dense bulk materials $[4,5,10]$.

Back pressure equal channel angular consolidation (BP-ECAC) is an innovative process to synthesise bulk 
materials from particles, which combined severe shearing with high pressure. In previous reports, micrometer-sized Al particles were consolidated by back pressure equal channel angular pressing $[13,18]$. Wu. X et al. [19] also reported that BP-ECAC was successfully applying to produce the aluminum matrix composites containing fine flyash particles, and discussed that this process not only produce ultrafine metal matrix composites but also greatly increase efficiency and thus reduce cost of production. In the present study, the BP-ECAP process was applied to prepare the bulk material of pure $\mathrm{Al}$ particles at room temperature, the $\mathrm{Al}$ powder wrapped in a pure aluminum sheath, and the back pressure block was arranged in the channel of the ECAP mold to improve the hydrostatic pressure, which can produce uniform shear in a large volume material. The evolutions of microstructure and densification mechanism were systematically investigated using an FEI-TECNAI G20 transmission electron microscope (TEM) operating at $200 \mathrm{kV}$, FEI field-emission scanning electron microscope (FE-SEM) and hardness testing showed good bonding between particles, full density and excellent fined grains.

\section{Experiment}

\subsection{Materials and Equipment}

The pure Al powder used was produced by aluminum melt atomization with the average size of $\sim 35 \mu \mathrm{m}$, the pure aluminum powder was selected as the experimental material due to their face-centered cubic structure and a total of 12 slip systems with good plasticity. When ECAP deformation was applied, it can get good deformation and achieve consolidation. In order to obtain sufficient strain accumulation effectively refine the structure during ECAP, the pure Al material was used as sheath, the pure Al powder wrapped in the sheath, and the deformation was carried out together with the sheath. However, the sheath was used to prevent contamination, these features make back pressure equal channel angular pressing (BP-ECAP) very suitable for practical applications by the industry.

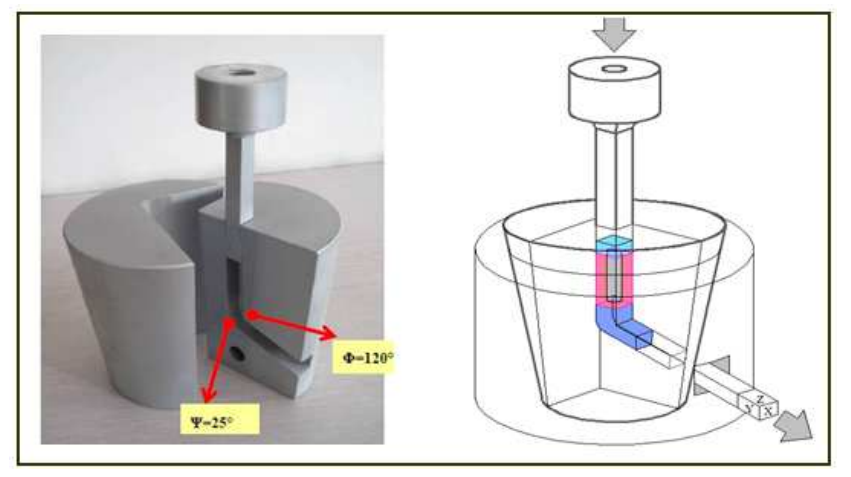

Figure 1. Schematic diagram of BE-ECAP process.

The BE-ECAP mold is composed of a die, sheath and a punch as shown in Figure 1. The mold is a split structure with the parting surface at the edge of the channel, so as to take out the sample smoothly. In order to provide enough radial pressing force for the extruding die so that there is no flash at the parting surface of the blank, the Mo type taper fit is adopted between the extruding die and the sheath. Cuboid samples with a dimension of $15 \mathrm{~mm} \times 15 \mathrm{~mm}$ prepared for BE-ECAP processing, and the ECAP process was carried out at room temperature with an average extrusion speed of $3 \mathrm{~mm} / \mathrm{min}$ using a die with $\varphi=90^{\circ} \mathrm{C}$ and $\psi=20^{\circ} \mathrm{C}(\varphi$ : inner arc of curvature; $\psi$ : outer arc of curvature) following the route $\mathrm{A}$ (the specimen is in the same direction between each pass).

\subsection{Experimental Procedures}

The pure Al powder wrapped in cylindrical shape Al sheath before the experiment (the red part in Figure 1b), and compacted to have a certain initial compaction. It is necessary to consider the thickness of the sheath to meet its strength, volume requirements and distribution of deformation zones. Because the deformation distribution in the deformation area is uneven, the deformation amount in the bottom area is relatively small, and an appropriate amount of margin is left to ensure the uniformity of powder deformation. In order to prevent powder loss during pressing and increase the back pressure, a gasket with a thickness of $5 \mathrm{~mm}$ was designed to the forward in the entrance channel (the blue part in Figure 1b), a back pressure block designed with 6063 alloy was placed in the exit channel to provide a constant back pressure (PB) during ECAP.

The microstructure of the sample was characterized by scanning electron microscopy (SEM) and transmission electron microscopy (TEM), the calibration method of the cross-sectional plane $\mathrm{X}$, the side- sectional plane $\mathrm{Y}$ and the top-sectional plane $\mathrm{Z}$ was shown in Figure 1b. For SEM observation, standard metallography procedures were followed to prepare the polished surface which was etched in a mixed acid solution of $0.5 \%$ hydrofluoric acid, $1.5 \%$ hydrochloric acid, $2.5 \%$ Nitric acid and $95.5 \%$ water for $20 \mathrm{~s}$ to reveal the grains. TEM was carried out in a FEI-G20 operating at $200 \mathrm{kV}$, thin foils for TEM observation were punched to discs of $3 \mathrm{~mm}$ in diameter, mechanically polished to $70 \mu \mathrm{m}$ and then ion-milled using Gatan691 plasma ion polisher. Examination of the mechanical properties of the samples was done using Rockwell hardness using $50 \mathrm{~g}$ and 25 s loading time.

\section{Results and Discussion}

\subsection{Microstructure Evolution of Al Powder During $B E-E C A P$}

Figure 2a shows the appearance and morphology of pure Al powder produced by atomization, the pure Al particle exhibited equiaxed grains with an average size of $\sim 35 \mu \mathrm{m}$ and a quantity of remaining coarse particles. In addition, the particles were of irregular shape as revealed in Figure 2b, and each particle contains substantially equiaxed grains with an average size of $\sim 6.36 \mu \mathrm{m}$. 

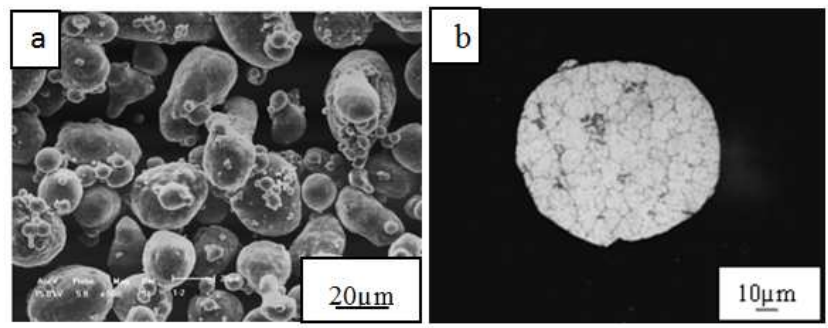

Figure 2. The a appearance and b microstructure of the as-received pure Al particles.

The specified composition of the as-received powder was as follows: $\mathrm{Al}(99.48 \%), \mathrm{Si}(0.1 \%), \mathrm{Fe}(0.15 \%), \mathrm{Cu}(0.02 \%)$, $\mathrm{O}(0.25 \%)$. The analysed composition of the as-received powder is shown in Table 1.

Among them, the composition of $\mathrm{Si}, \mathrm{Fe}, \mathrm{Cu}$ and $\mathrm{Al}$ is consistent with the standard composition of commercial pure aluminum. However, the powder material had a higher oxygen content of $0.25 \mathrm{wt} . \%$ (Table 1 ). This was obviously due to the surface oxide on the as-received Al particles because of the larger specific surface area.

Table 1. Chemical compositions of the as-received Al powder (wt.\%).

\begin{tabular}{lllll}
\hline $\mathbf{S i}$ & $\mathbf{F e}$ & $\mathbf{C u}$ & $\mathbf{O}$ & $\mathbf{A l}$ \\
\hline $0.1 \%$ & $0.15 \%$ & $0.02 \%$ & 0.25 & $99.48 \%$ \\
\hline
\end{tabular}

\subsection{Microstructure Analysis After BE-ECAP Processed for One Pass}

Figure 3 presents the SEM images of the $\mathrm{X}$ plane and $\mathrm{Y}$ plane after BE-ECAP for 1 pass at room temperature. Good bonging between particles was obvious with no pores observed, a large number of micro-pores were closed, and the density has been significantly improved, which was basically consistent with the results of the investigations [13]. The microstructure of the $\mathrm{X}$ plane remains unchanged compared with the as-received pure Al powder (Figure 3a). The grains of the $\mathrm{Y}$ plane were obviously elongated and refined significantly (Figure $3 \mathrm{~b}$ ) with the average size of $\sim 22.6 \mu \mathrm{m}$, considerably finer than the as-received particles. It is uniform and the shear marks are clearly visible.
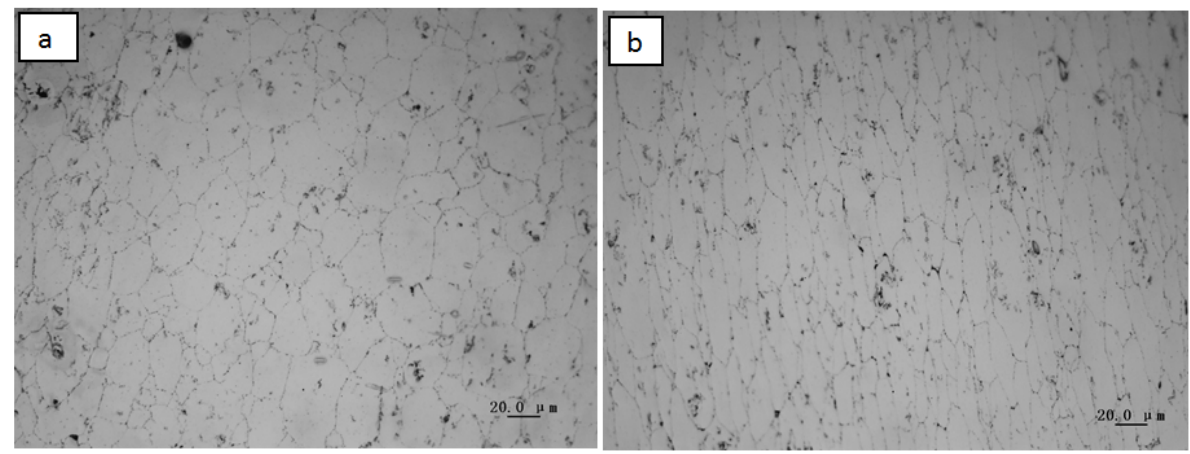

Figure 3. The microstructure of a X plane and $b$ Y plane after BE-ECAP for 1 pass.

As mentioned above results show that the powder area has not entered the front of the corner in the mold at the outset of the BE-ECAP. The powder of matrix and pore morphology unchanged due to the small amount of deformation compared with the as-received sample. After the particles enters the corner area, the microstructure and morphology of the sample has changed significantly due to the strong shear deformation, the particles were moved, rotated, deformed and fractured to mechanically mesh and boding consolidation, as observed also by other [10].

Figure 4 shows the TEM microstructure of the Y plane after BE-ECAP for pass. Severely shear deformation occured between particles and a large strain was generated inside the matrix structure, which promoted a large number of dislocations inside the grain. After 1 BE-ECAP pass, a clear dislocation structure had generally formed inside the grains and entangled dislocations were stacked together to form a dislocation wall. It is clear that the dislocations within the grains move toward the grain boundaries (Figure 4 a), But the grain boundaries are relatively fuzzy (arrow position) with more completely equiaxed subgrains (indicated by the arrow in Figure 4) can be seen inside the local grains.
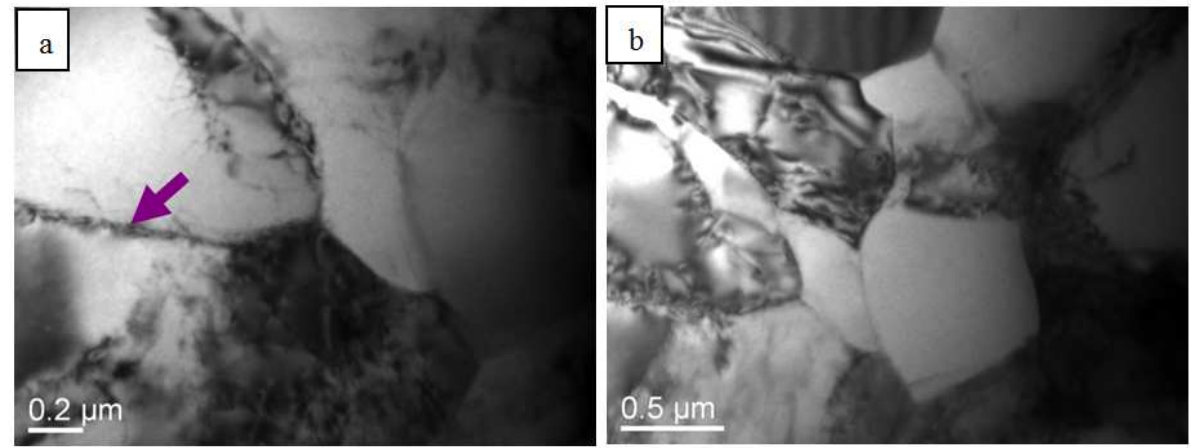

Figure 4. The morphology of a dislocation and $b$ subgrain on Y plane after BE-ECAP for 1 pass. 


\subsection{Microstructure Analysis After BE-ECAP Processed for Two Pass}

Figure 5 shows the SEM microstructure of $\mathrm{X}$ plane and $\mathrm{Y}$ plane after BE-ECAP for 2 pass. The microstructure of $\mathrm{X}$ plane remains unchanged compared with the one pass.

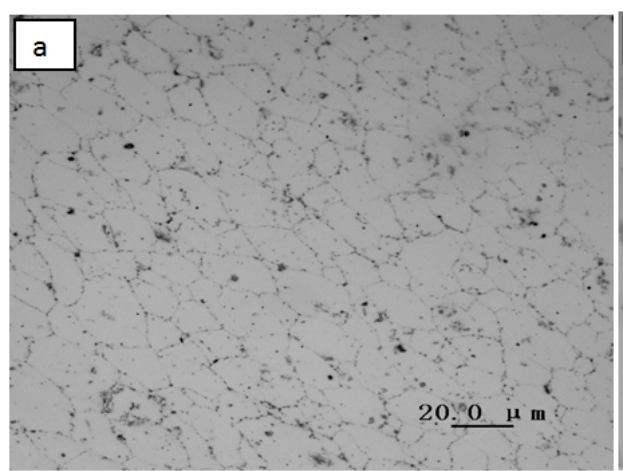

Figure 5. The microstructure of a X plane and $b$ Y plane after BE-ECAP for 2 pass

Figure 6 shows the TEM microstructure of Y plane after BE-ECAP for 2 pass. It can be seen that with the increase of shear strain, the proliferation of dislocation promotes the grain to be further refined compared with the 1 pass, which is consistent with the research results in Ref. [20]. The movement of dislocations (as shown in Figure 6a) forming dislocation grid, which is indicated by the arrow
However, the microstructure of the $\mathrm{Y}$ plane was further elongated into a band-like structure with the shear marks can be observed, the grains were refined and the pores were closed to further increase the density compared with the 1 pass.

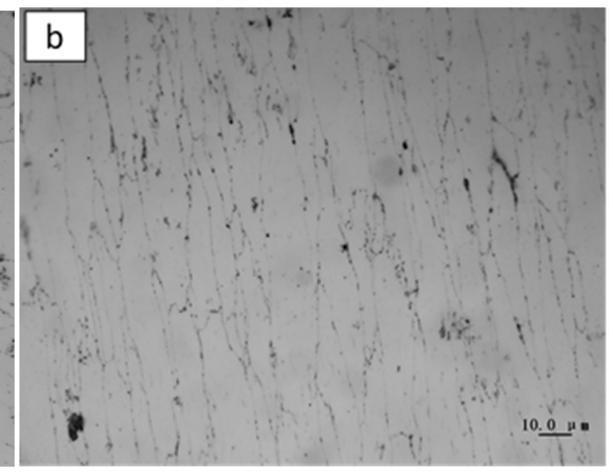

in the Figure. Complete sub-grains and partially-formed sub-grains were formed in part of the grains (as shown in Figure 6b), and their sizes and shapes were not very uniform with no obvious dislocation observed. Dislocation accumulation can still be observed at the sub grain boundary, while some sub grain boundaries tend to be flat.
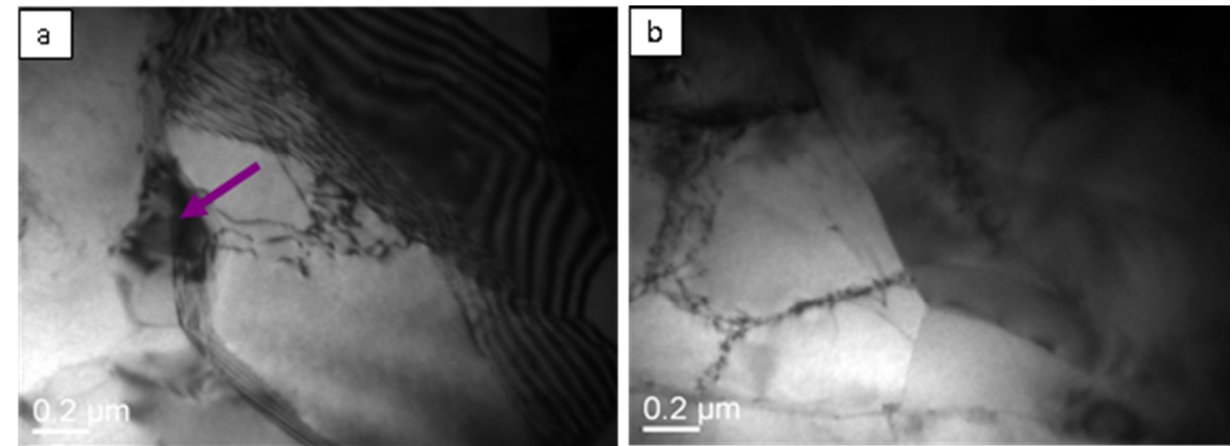

Figure 6. The morphology of a dislocation and $b$ subgrain on Y plane after BE-ECAP for 2 pass.

\subsection{Microstructure Analysis After BE-ECAP Processed for Four Pass}

Figure 7 shows the SEM microstructure of X plane and $Y$ plane after BE-ECAP for 4 pass. It was observed that the
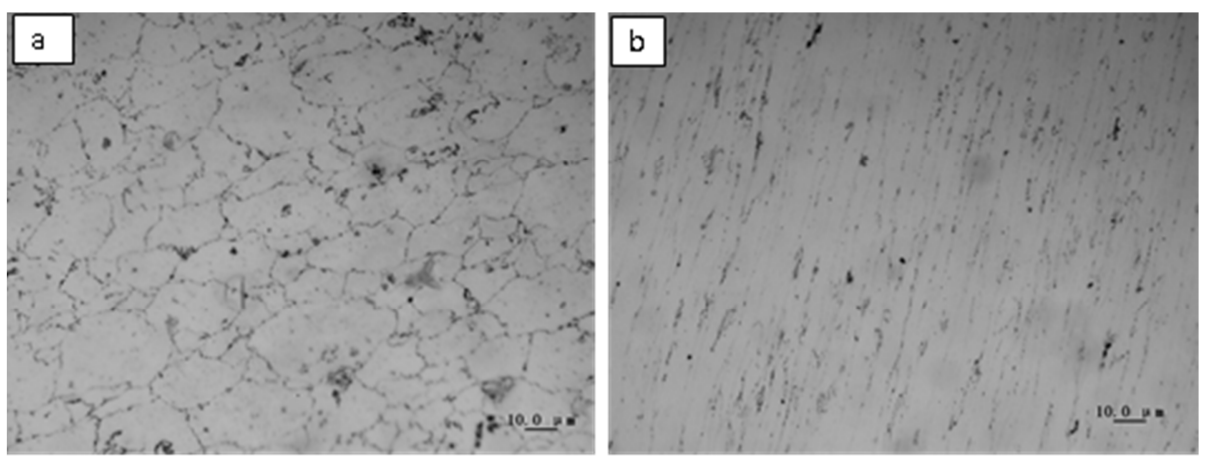

Figure 7. The microstructure of a X plane and $b$ Y plane after BE-ECAP for 4 pass.

grains were further refined on the X-Plane with an average particle size of $\sim 10.62 \mu \mathrm{m}$ with the increase of accumulated strain. In the Y plane, the grains were further elongated and the morphology was similar to the present in Figure 5. 
Figure 8 shows the TEM microstructure of the cross section after BE-ECAP for 4 pass. It can be seen that the grains are further refined and the sub grain boundaries inside the grains are more perfect, because of the dislocations inside the grains also move to the sub grain boundaries, accumulate, entangle and annihilate at the sub grain boundaries, the sub grains are broken and rotated continuously, and the grain size distribution tends to be uniform. While the grain is relatively clean with no dislocation was observed and the grain boundary tends to be flat.

When increasing the number of BE-ECAP passes from 1 to 4 , the grains refinement subsequently increase, the first two passes had the best effect, and the last pass had a weaker effect. With an increase in the number of BE-ECAP passes and the cumulative strain, the uniformity and density of the grain size distribution within the sample were improved, and the matrix material also presents a higher work-hardening.

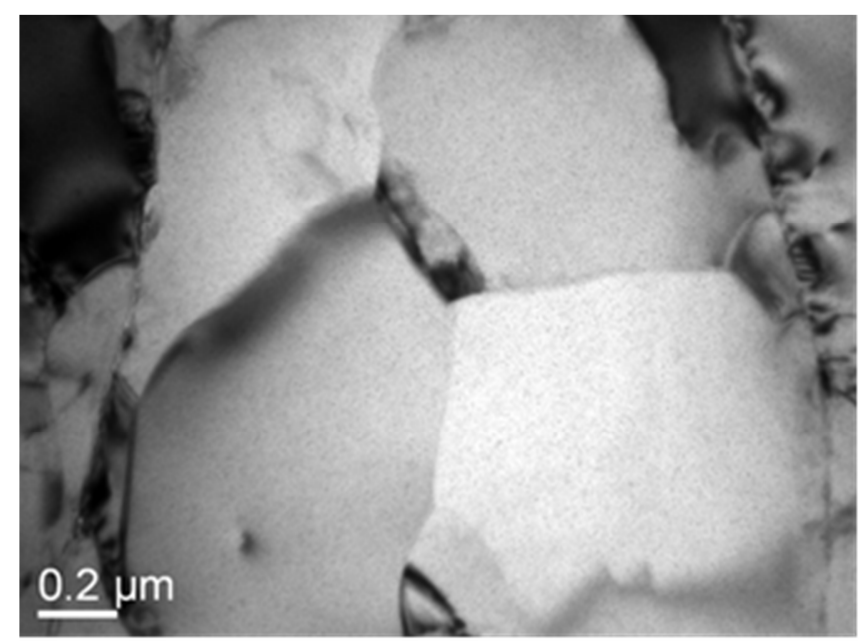

Figure 8. The TEM microstructures at X plane after 4 passes.

\subsection{Evolution of Density and Micro-hardness on Each Pass}

The sample cover was peeled off by lathe after each pass, the density of the materials was measured based on the Archimedes principle using samples of about $2 \mathrm{~cm}^{3}$ in volume and polished on all surfaces [13]. For mechanical properties, the Vickers hardness (HV) was measured using $50 \mathrm{~g}$ load and 25 s loading time. Ten Points were tested for each specimen.

Table 2 shows the density and the HV values of the sample. It can be seen that the pure aluminum powder was effectively consolidated and densified after only one pass of consolidation with the relative density of $97.0 \%$ and the micro-hardness of $38.6 \mathrm{HV}$, an increase of approximately $18.4 \%$. After that, the material structure was further refined and dense during the BE-ECAP process, but the increase in relative density and micro-hardness gradually slowed down, eventually $99.2 \%$ and $44 \mathrm{HV}$ respectively after BE-ECAP for 4 pass. This was consistent with observations in other investigations [21]. In comparison, the materials did not gain full density even after multiple passes in ECA deformation without back pressure [20, 21].
Table 2. Density value and Vickers microhardness of the sample with different passes.

\begin{tabular}{lll}
\hline Sample & $\begin{array}{l}\text { Density }\left(\mathbf{g} / \mathbf{c m}^{3}\right) / \text { Relative } \\
\text { density }(\%)\end{array}$ & HV $\left(\mathbf{K g} / \mathbf{m m}^{2}\right)$ \\
\hline Commercial Pure Al & $2.67 / 100$ & $32.6 \mathrm{HV}$ \\
1 pass & $2.59 / 97.0$ & $38.6 \mathrm{HV}$ \\
2 pass & $2.62 / 98.1$ & $41.2 \mathrm{HV}$ \\
3 pass & $2.63 / 98.5$ & $42.1 \mathrm{HV}$ \\
4 pass & $2.65 / 99.2$ & $44 \mathrm{HV}$ \\
\hline
\end{tabular}

The above results show that excellent bonding between particles can be achieved at room temperatures by forcing them to undergo severe shear deformation under moderate compressive stress [22]. Pure Al particles in the caning were displaced and deformed under the stress, and the density of the sample changed regularly with the BE-ECAP pass. When the particles had not entered the corner of the mold, the powder was displaced to fill the pores due to the stress. The powder's arch bridge effect was destroyed and the density of the sample increased rapidly. The particles entered the intersection of the two channels and subjected to a large shear deformation. When the stress exceeded the critical stress of the powder, some large particles were crushed and filled the gaps between the particles. Moreover, the shearing also forced the surface oxide layers surrounding the metal particles are ruptured and exposed freshly clean surfaces of the particles, ensured good bonding between them [19, 23], which resulted in the density of the sample was further increased. In the subsequent BE-ECAP passes, although the pores of the specimen further closed and the density was further increased, the increase range was inferior to the first pass. After BE-ECAP for 4 pass, the density of the sample was close to the theoretical density of pure aluminum. It has demonstrated that this process can achieve extremely ideal powder compacting effect. The plastic deformation of the particles and the effect of the back pressure block caused the metal in the deformation zone to have a large compressive stress, which promoted the consolidation and alloying of the aluminum powder.

\section{Conclusion}

(1) With the application of a back pressure, which can make the pure Al powder plastically deform and consolidate under the hydrostatic pressure, and full density and good bonding throughout the volume was reached after the very first passage at room temperature.

(2) In the process of powder consolidation, the powder was displaced and filled with pores undergo severe shear deformation. When the powder was subjected to the stress exceeding the critical stress, it began to deform and the arch bridge effect of the powder was destroyed. The effect of the filled pores effect enhanced the density of the sample, which was approach to the theoretical density of pure Al after BE-ECAP for 4 pass.

(3) The grain was severely refined from $\sim 35 \mu \mathrm{m}$ as-received state to $10.62 \mu \mathrm{m}$ just one pass of BE-ECAP. After BE-ECAP for multiple passes, although the powder was further refined, the increased magnitudes seemed to be 
small. The grain refining mechanism was the deformation process of BE-ECAP, which caused the dislocations generated inside the grains to continuously move to the grain boundaries, accumulation, entanglement and annihilation at the grain boundaries, made the grains constantly broken and the grain structure significantly refined.

\section{Acknowledgements}

This work was supported by the National Natural Science Foundation of China (No. 11574043, U1760105).

\section{References}

[1] K Matsuki, T Aida, T Takeuchi, J Kusui, K. Yokoe. Microstructural characteristics and superplastic like behavior in aluminum powder alloy consolidated by equal channel angular pressing. Acta Materialia, 2000 (48): 2625-2632.

[2] O N Senkov, S V Senkova, J M Scott, D B Miracle. Compaction of amorphous aluminum alloy powder by direct extrusion and equal channel angular extrusion. Materials Science and Engineering A, 2005 (393): 12-21.

[3] M H Paydar, M Reihanian, E Bagherpour, M Sharifzadeh, M Zarinejad, T A Dean. Consolidation of Al particles through forward extrusion-equal channel angular pressing (FE-ECAP). Materials Letters, 2008 (62): 3266-3268.

[4] Kondaiah Gudimetla, Ramesh Kumar S, Ravisankar B, Prasad Prathipati R and Kumaran S. Consolidation of commercial pure aluminum particles by hot ECAP. Materials Science and Engineering, 2018 (330): 1-6.

[5] Gudimetla K, Kumar S R, Ravisankar B and Kumaran S. Densification of Al 5083 mechanically alloyed powder by equal channel angular pressing, Transction of the Indian Institute of Metals, 2015 (68): s171-s176.

[6] Gudimetla K, Jampana G V, Kumar S R, Ravisankar B and Kumaran S. Effect of Equal Channel Angular Pressing on Densification Behavior of Al 5083 Alloy Powder. Materials Science Forum, 2015 (830): 63-66.

[7] Xiao-xi WANG, Min HE, Zhen ZHU, Ke-min XUE, Ping LI. Influence of twist extrusion process on consolidation of pure aluminum powder in tubes by equal channel angular pressing and torsion. Transactions of Nonferrous Metals Society of China, 2015 (25): 2122-2129.

[8] M Jahedi, M H Paydar. Study on the feasibility of the torsion extrusion (TE) process as a severe plastic deformation method for consolidation of $\mathrm{Al}$ powder. Materials Science and Engineering A, 2010 (527): 5273-5279.

[9] Wang X X, Xue K M, Li P, et al. Equal channel angular pressing and torsion of pure $\mathrm{Al}$ powder in tubes [C] //Advanced Materials Research. Trans Tech Publications, 2010, 97: 1109-1115.

[10] Wang X, Min H E, Zhen Z H U, et al. Influence of twist extrusion process on consolidation of pure aluminum powder in tubes by equal channel angular pressing and torsion $[\mathrm{J}]$.
Transactions of Nonferrous Metals Society of China, 2015, 25 (7): 2122-2129.

[11] Mani B, Jahedi $M$ and Paydar M H. Consolidation of commercial pure aluminum powder by torsional equal channel angular pressing (T-ECAP) at room temperature, Powder Technology, 2012 (219): 1-8.

[12] Li Ping, Xue Ke-min, Wang Xiao-xi. Refinement and consolidation of pure Al particles by equal channel angular pressing and torsion. Transactions of Nonferrous Metals Society of China, 2014, 24 (5): 1289-1294.

[13] K. Xia, X Wu. Back pressure equal channel angular consolidation of pure Al particles. Scripta Materialia, 2005 (53): 1225-1229

[14] S Goussous, W Xu, X Wu, K Xia. Al-C nanocomposites consolidated by back pressure equal channel angular pressing. Composites Science and Technology, 2009 (69): 1997-2001.

[15] X Wu, W Xu, K Xia. Pure aluminum with different grain size distributions by consolidation of particles using equal channel angular pressing with back pressure. Materials Science and Engineering A, 2008 (493) 241-245.

[16] Riccardo Casati, Maurizio Vedani, David Dellasega, Paola Bassani and Ausonio Tuissi. Consolidated $\mathrm{Al} / \mathrm{Al}_{2} \mathrm{O}_{3}$ nanocomposites by equal channel angular pressing and hot extrusion. Materials and Manufacturing Processes, 2015 (30): 1218-1222.

[17] Derakhshandeh Haghigh Reza, Jahromi Seyed and Ahmad Jenabali. The Effect of Multi-pass Equal-Channel Angular Pressing (ECAP) for Consolidation of Aluminum-Nano Alumina Composite Powder on Wear Resistance, Journal of Materials Engineering and Performance 2016, 25 (2): 687-696.

[18] Xia K, Wu X, Honma T, et al. Ultrafine pure aluminium through back pressure equal channel angular consolidation (BP-ECAC) of particles [J]. Journal of materials science, 2007, 42 (5): 1551-1560.

[19] Wu X, Xia K. Back pressure equal channel angular consolidation-Application in producing aluminium matrix composites with fine flyash particles [J]. Journal of materials processing technology, 2007, 192: 355-359.

[20] Venkatraman R, Raghuraman S, Balaji R, et al. Investigation of tensile property and pore closure behavior and the influence of processing route during equal channel angular pressing of pure aluminum powder compacts [C]//Applied Mechanics and Materials. Trans Tech Publications Ltd, 2014, 592: 444-450.

[21] Gudimetla K, Chaithanyakrushna B, Chandra Sekhar K, et al. Densification and Consolidation of Al 5083 Alloy Powder by Equal Channel Angular Pressing [C]//Applied Mechanics and Materials. Trans Tech Publications Ltd, 2014, 592: 112-116.

[22] $\mathrm{Xu} \mathrm{W}, \mathrm{Wu} \mathrm{X}$, Honma $\mathrm{T}$, et al. Nanostructured $\mathrm{Al}-\mathrm{Al}_{2} \mathrm{O}_{3}$ composite formed in situ during consolidation of ultrafine $\mathrm{Al}$ particles by back pressure equal channel angular pressing [J]. Acta Materialia, 2009, 57 (14): 4321-4330.

[23] $\mathrm{Wu} \mathrm{X} \mathrm{L}, \mathrm{Xu} \mathrm{W}$, Kubota M, et al. Bulk Mg produced by back pressure equal channel angular consolidation (BP-ECAC) [C] //Materials Science Forum. Trans Tech Publications, 2008, 584: 114-118. 